\title{
Giant Splenectomy
}

\author{
*Reinaldo Silvestre \\ La Habana University, Cuba
}

Submission: March 21, 2016; Published: September 07, 2016

*Corresponding author: Reinaldo Silvestre, La Habana University, 1590w 58st, HIALEAH FL, 33012, Cuba.

Abstract

Giant Splenectomy Clinical Indications Etiology Complications and Procedures History of their first splenectomy of a Giant Spleen in Equatorial Guinea, Malabo Hospital 1983.

\section{Introduction}

The motivation to write this article, arise when I was a young gal surgeon working as a volunteer at the Republic of Equatorial Guinea, Member of the Cuban Medical Team 1983-1985 [1].

\section{Concept}

A splenectomy is a surgical procedure that removes the spleen totally. There is a wrong procedure called partial splenectomy that historically ha bring a lot of post operatory complications to patients, so that we are in favor of the total splenectomy to save the patient's life [2].

\section{History}

The history mentioned that was an Austrian Surgeon Hermann Schloffer who performed the first splenectomy but we found that the Italian Surgeon Ambrosia Pare was the first who took away the spleen from children after an accident in Italy [3].

\section{Indications}

The most common indication of the splenectomy is because of rupture by trauma. But there is a lot of disorders that are playing a role in the spleen hematopoietic function and others than are real indication of splenectomy in a variety of conditions the spleen can enlarged and those conditions are Malaria, Blood problems, Leukemia, Mononucleosis and most commonly in Cancers of the Lymphatic system like are Lymphomas etc. There are specials conditions that make surgeons to perform a splenectomy that we are going to remark. When the spleen start to destroy platelets and red cells, Idiopathic thrombocytopenic purpura, Autoimmune conditions, Lymphomas, Spontaneous ruptures, Physical trauma, Metastasis from Gastric Carcinoma or Colon $\mathrm{Ca}$, When using the spleen artery to make bypass, Severe Hemolytic Anemia, Treatment of (PK) Deficiency, Splenomegalie that bring risk to the patient life, the classical indication is the traumatic rupture.

\section{Procedures}

\section{Laparoscopic Splenectomy}

This is the fast and simpler approach, but it has to be performed for a surgeon with a good training in this kind of minimum access. Also in the facility with enough conditions in case of an emergency during the surgery [4]. In our experience accidents are very frequents in laparoscopic splenectomy [5], post operatory bleeding from small arteries is one of the problems, if the surgeon let a drain in place is a more secure the Post-op.

\section{Open Partial Splenectomy}

Is not a good procedure, because it is not saving, and we are against surgeons and schools that promoted this kind of surgery. Any partial resection of the spleen is a high risk surgery for the patient life [6].

\section{Open Total Splenectomy}

This is the best procedure to removes the spleen, Usually when the surgeon open the abdominal cavity with any kind of incision, we prefer left paramedical, supraumbilical approach then start to release the spleen for different attachments like diaphragmatic, gastric and colic. you can release the spleen from the diaphragm easily with your hand then, after you clip and tied the short gastric arteries, the spleen will be hanging from his pediculus, the surgeon make posterior-anterior dislocation of the organ and will clip and suture the pediculus from the back Usually we like to apply double suture which is more save. Always let a drain in place.

Now we are Going to Explain the First Giant Splenectomy that we Performed for the First Time in the History of the Republic of Equatorial Guinea in 1983

Patient Name- Antigo MBA, AGE 45 YEARS. I was a volunteer surgeon of the Cuban medical team at Malabo Hospital [7], the 
nurse from emergency ward called Dr. Reinaldo I need you to come and see this patient with a very big belly! When I saw the patient I found that a big mass was into his abdominal cavity and the mass was taking almost the whole cavity, I said oh my God what is this? That time in Malabo Hospital we don't had ultrasound, no scans, nothing just a small blood count a simple x-ray and my hands over his abdomen. Of course I knew that the incidence of Malaria in the country was very high and many patients can develop chronic diseases that slowly are making this king of giant Splenomegalie [8]. We prepared the patient to perform the first giant splenectomy in Equatorial Guinea.

The giant splenectomy is totally different to the procedure that we mentioned before because here the surgeon have to go anterior to posterior and will going to release more attachments that you usually find because this abnormal grow bring new attachments and more difficult dissection of the arteries. The most important step is that you can't removed the spleen full of blood because the patient will fall in hipovolemic shock, so that, the surgeon has to clip first the spleen artery, and doing this for 15 or 20 minutes the spleen will continue sending blood out of his parenquima and give blood supply to the blood stream, after that time you can clip also the spleen vein and always suture the artery and the vein at the pediculus with double trans-suture with silk. We also gave some vasoconstrictor IV to the patient before to clip the vein making sure that we took more blood out of the organ. Closing the cavity like usually and always let a big drain tube in place. This was an special experience that we like to provide to the new generation of surgeons.

\section{Conclusion}

Also, we would like to mention, that in actually you have some vaccines to give to patients before the splenectomy because how the immune defense will be low, some patients can develop Pneumonia, Meningococcal infections, also infections for H.INFLUENZA so, is very important that the surgeon prevent complications that are in relation with the poor immune defense. Some studies are speaking of diabetes that appear after splenectomy and chronic liver diseases but in our experience we never found that correlations. All that we the older surgeon's professors can do to provide information useful to the new generations of the surgeons [9].

\section{References}

1. Revision de la incision de Singlenton para la Esplenectomia/ complicaciones. Hospital Pity Fajardo La Habana, Cuba.

2. Splenectomy. Mayo Clinics. Definition pp: 2001-4837

3. Davies JM (2001) British Guideline up-date. BMJ 320: 430-434.

4. Brandow AM, Nelson. Splenectomy Pediatrics surgery

5. C kosmidis (2009) Laparoscopy splenectomy non parasitic splenic cyst.

6. Laparoscopy partial splenectomy (2004) Bailez M Elmo 8(2): 147-151.

7. Spenectomia Indicaciones Tecnica (1977) Revista Cubana de Cirugia General.

8. Surgical Splenectomy book of surgery also vaccination before surgery (2012). Charles J Yeo 628-636.

9. Christophers Kosmidis (2009) Laparoscopy splenectomy for giant hemangioma cases journal. Case Report 2: 10 . 